DOI:

\title{
MIXED METHODS RESEARCH IN TOURISM: A SYSTEMATIC SEQUENTIAL APPROACH
}

\author{
Peter Mason*, Marcjanna M. Augustyn**, \\ Arthur Seakhoa-King***
}

\begin{abstract}
Purpose: This article discusses the use of mixed methods research in tourism. It provides the rationale for the use of mixed methods and discusses the context in which this was chosen and used. It outlines the major research philosophies, and their advantages and disadvantages, and discusses the systematic, sequential, step-by-step research processes that were employed. The article also analyses the potential usefulness of specific qualitative data collection techniques. Method: The context of the article was a study investigating what tourists associate with tourism destination quality (henceforth referred to as the TDQ study). The article indicates the nature of the phases of research in the TDQ study, beginning with the qualitative exploratory research involved. It discusses how questions were designed, and the pre-testing and piloting of questions and research techniques. It provides details on the main qualitative and subsequent quantitative phases of the research.

Findings: The article argues that an initial systematic qualitative phase of research can be used within an overall mixed methods approach to precede a quantitative phase with a successful outcome in terms of robust and rigorous research findings. Additionally, the results of the pilot study data indicate the superiority of the in-depth interviews technique over focus group interviews and open-ended questionnaires in terms of the technique's effectiveness, efficiency, and ability to generate in-depth, detailed and unique data.

Research and conclusion limitation: The article discusses only one case study in detail.

Practical implication: Although not intended to be prescriptive, this article could be used as a blueprint for those involved in research involving similar methodology.

Originality: This article advances knowledge of the effectiveness of mixed method methodologies and techniques in tourism studies. By providing a detailed account of a systematic sequential mixed method approach, the paper provides insights into and a potential blueprint for researchers interested in conducting such research.

Type of paper: research methodology article.

Keywords: mixed methods, pragmatism, exploratory research, qualitative research, quantitative research, systematic sequential research design, tourism destination quality.

* (D) https://orcid.org/0000-0002-8732-863; Prof. (Ph.D.), London Metropolitan University, London, UK; e-mail: peter.mason51@sky.com.

** (D) https://orcid.org/0000-0002-8270-3839; Prof. (Professor), Bournemouth University, Poole, UK; e-mail: maugustyn@bournemouth.ac.uk.

*** (D https://orcid.org/0000-0001-7624-1386; Dr. (Ph.D.), Mohammed bin Rashid School of Government, Dubai, United Arab Emirates; e-mail: seakhoa@hotmail.com.
\end{abstract}




\section{Introduction}

The use of mixed methods, although not new, is a fairly recent phenomenon in tourism research [Khoo-Lattimore, Mura, Yung 2019; Mason, Augustyn, Seakhoa-King 2010; Seakhoa-King, Augustyn, Mason 2021] and there have been relatively few articles employing mixed methods compared with the use of just one research philosophy, be it either quantitative or qualitative [Khoo-Latimore et al., 2019] Early research in tourism, going back to at least the 1960s, was largely quantitative [Mason 2017]. The starting point for such quantitative research was often government or company documents, and this approach was frequently supported by the primary research technique of the questionnaire survey, which usually sought generalisable results from a sample of respondents who provided mainly short answers, via closed-ended questions, that could be statistically analysed.

Reaction against this quantitative approach in tourism research was appearing during the 1970s in the work of sociologists and anthropologists such as E. Cohen [1972] and G. Dann [1977] For such researchers, the use of interviews and focus groups was relatively common [Lincoln, Guba 1985], as they were interested in views and opinions and these can best be expressed in depth and detail using the words of respondents themselves, rather than responses generated via the use of author-designed, closed-ended questions, such as those on a questionnaire, it was argued [Cresswell 2018; Mason 2014].

Although the paragraphs above refer briefly to the nature of the two predominant research traditions used in tourism research over the past fifty years, a third approach was being applied during the last thirty years or so. This, mixed methods research, is less well known than either of the two other approaches, partly because it is relatively new [Teddlie, Tashakkori 2009]. As it is less well known, it is defined below. A. Teddlie and A. Tashakkori, major authors discussing mixed methods, have indicated it presents an alternative to the quantitative and qualitative traditions by:

'advocating the use of whatever methodological tools are required to answer the research questions under study' [2009, p. 6].

In terms of research design, A. Tashakkori and A. Teddlie [2003] defined mixed methods research as where both quantitative and qualitative approaches are used in types of questions, research methods, data collection and analysis, while A. Tashakkori and J. Cresswell, [2007] also stressed the links between the two main research traditions, when defining mixed methods as research where the investigator collects and analyses, and integrates findings, using both qualitative and quantitative approaches.

However, the use of mixed methods is frequently viewed as controversial [Teddlie, Tashakkori, 2009; Timans, Wouters, Heilbron 2019] and for some 
researchers combining quantitative and qualitative design, data collection and analytical processes is regarded as inappropriate, as the underlying philosophies are incompatible [Guba 1987; Smith, Heshusius 1986]. This issue of potential incompatibility is discussed later in this section, and in more detail in that following this one, which focuses on research philosophy.

Nevertheless, it is appropriate here to indicate the thinking that took place in relation to the main context for this article, where mixed methods were used. Whilst questionnaires may be appropriate where pre-existing published work can be used to create questions for a new context, there is much that is still unknown, or little understood in the relatively new field of tourism studies. This means that the type of questions to be asked are not necessarily obvious, and there is little or no guidance from previously published work. In this context, question design may not be straightforward, and the use of a questionnaire survey is probably unsuitable. Hence, a quantitative approach is not necessarily viewed as appropriate.

This was the context for the study discussed later in this article. The focus of this (the TDQ study) was tourism destination quality, a topic with some research already that had used the services marketing conceptualisation of quality, but where there was a lack of research on tourists' views on what tourism destination quality is. By definition, any research that investigates new topics, is likely to be of an exploratory nature [Mason et al, 2010]. However, there appears to be little guidance on how to conduct exploratory research in the tourism field [Stebbins 2001].

This situation poses a significant dilemma for researchers who wish to push back the boundaries of tourism knowledge and yet conduct research that is valid, reliable and robust. The preference may be for quantitative techniques but creating questions for a new topic, with hardly any prior research, could be difficult. On the other hand, researchers are likely to be aware of the criticisms of qualitative techniques, as for examples interviews are criticised for lacking rigor and being not scientific and the results not being generalisable to the whole population [Timans et al., 2019; Cresswell 2018; Mason 2014]. As indicated briefly above, for many researchers there is potentially an even more important dilemma: each of the two main research approaches, the quantitative and qualitative, has a different philosophy, as well as using different techniques. Hence for some, the two research philosophies are incompatible. So, a researcher who has only ever used quantitative techniques will not only have to learn about alternative techniques but may need to change their perspective on the nature of research itself, as well as the underlying principles that guide it.

This article therefore discusses the rationale for the use of mixed methods. Although, this paper is largely concerned with practical steps to achieve mixed methods research, rather than focusing on the philosophical issues, the paper briefly outlines the major research philosophies, and their advantages and disadvantages. 


\section{Research Philosophy}

According to T. Eldabi, Z. Irani, R.J. Paul and P. E. Love [2002], research philosophies can be grouped into two general categories: positivism and interpretivism, with each representing different, if not competing views on how to conduct research. As J. Phillimore and L. Goodson [2004] note, any research philosophy adopted in a study should fit the research problem that the researcher intends to investigate, implying researchers need to choose one or other research category.

The research philosophy of positivism, until fairly recently regarded as the dominant approach in tourism research [Khoo-Lattimore et al., 2019; Riley, Love 2000; Walle 1997], views reality as singular and independent of the researcher [Creswell 2018; Decrop 1999; Lincoln, Guba 1985]. It also regards reality as something which can be measured objectively, for example, by using a quantitative research instrument [Teddlie, Tashakkori 2009; Davies 2003].

However, the research philosophy of interpretivism rejects the idea of a single objectively measurable reality, positing instead the existence of subjective, multiple constructed realities [Cresswell 2018; Davies 2003; Lincoln, Guba 1985]. The individuals involved in the research situation here, including the researcher, those being investigated, and the reader or audience interpreting the research, are regarded as the creators of these realities [Creswell 2018]. Interpretivists contend that multiple realities can only be captured through the employment of less rigid data collection techniques than generally used in quantitative research [Cresswell, Plano Clark 2007; Bernard 2000].

The research philosophies of positivism and interpretivism also differ in their assumptions about the relationship between reality and the researcher [Creswell 2018]. Interpretivism has its roots in 'Verstehen' or the empathetic understanding tradition of Max Weber. Here, it is argued that to understand peoples' behaviour, researchers need to put themselves in the place of the enquiry subjects [Jennings 2011]. Therefore, interpretivist researchers try to minimise the distance between themselves and respondents [Creswell 2018]. So, the interpretivist tries to get inside the respondents' minds and see the world from their view [Jennings 2011]. Interpretivists have been described as observers 'from the inside', the term used is 'emic' [Teddlie, Tashakkori 2009; Phillimore, Goodson 2004; Walle 1997]. However, positivist researchers try to provide an independent, outsider's account of the research process, known as an 'etic' approach [Teddlie, Tashakkori 2009; Phillimore and Goodson 2004; Walle 1997] to ensure that the researcher's biases are excluded [Creswell 2018].

Although, the two research philosophies may seem incompatible, they are being increasingly combined in the social sciences, including in tourism 
research [Timans et al., 2019; Mason et al., 2010; Seakhoa-King et al., 2021] and what makes it possible to use them together in one study, is the underlying philosophy of the majority of mixed methods research, that of pragmatism [Teddlie. Tashakkori 2009]. Pragmatism has been defined as a research approach that:

debunks concepts such as 'truth' and 'reality' and focuses instead on 'what works' as the truth regarding the concepts under investigation. Pragmatism rejects the either/or choices of the paradigm wars (and) advocates for the use of mixed methods in research [Tashakkori, Teddlie 2003, p. 713].

Despite mixed methods being a fairly new research approach, a number of different types can be identified. For example, J.W. Creswell and V. Plano Clark [2007] identified 12 different classification systems in mixed methods, drawn from several fields in the social sciences, including nursing, health, education and behavioural studies. J.W. Cresswell [2009, based on Cresswell, Plano Clark, Gutman, Hanson 2003], suggested there are six types of mixed methods research. There are two major groupings in this sixfold typology, based on whether different research approaches are used sequential$l y$ or concurrently [Cresswell 2009]. In relation to sequential research, one approach begins with qualitative research and is then followed by a quantitative phase, and this is termed sequential exploratory research by J.W. Cresswell [2009]. Research starting with a quantitative approach, followed by a qualitative phase is termed sequential explanatory research [Creswell 2009]. The third type of sequential research uses a specific theoretical perspective from the beginning, which shapes the direction of the research, and the sequence of the two-phase research can begin with either a quantitative or a qualitative approach and J.W. Creswell terms this sequential transformative research. In terms of the second major grouping, Cresswell indicates there is concurrent triangulation, where both qualitative and quantitative data are collected concurrently. In this approach, the intention is to give equal weighting to each of the qualitative and quantitative approaches. However, in contrast, in the concurrent embedded approach, there is one predominant approach, and the secondary supporting approach (quantitative or qualitative) is embedded within the main approach. Finally, in this six-fold typology, there is the transformative concurrent approach where the research is guided by the use of a specific theory in the collection of both quantitative and qualitative data, concurrently [Cresswell 2009]

However, the major purpose of this article is not to focus on the philosophical issues of the different research paradigms, but instead to show 'what works' [Tashakkori, Teddlie 2003] by indicating the practical steps of mixed methods research, through a discussion of the sequential stages of the TDQ study, and reasons for the methodological choices made. This in- 
volves discussion of the selection of the overall research approach, data collection techniques, sampling procedures and analytical techniques. Nevertheless, it does not discuss the results in any detail [for an in-depth discussion of these see Seakhoa-King et al., 2021].

\section{The TDQ Study: Systematic Sequential Mixed Methods Approach}

This section of the article indicates the nature of the phases of research in the TDQ study, beginning with the exploratory research involved. It discusses how questions were designed, and the pre-testing and piloting of questions. It provides details on the main qualitative and subsequent quantitative phases of the research.

At the start of the research process for the TDQ study, two significant questions required answers. These were:

a) What type of research problem/issue was being investigated?

b) How should research be conducted once the nature of the research problem/issue had been clearly identified?

The response to Question (a) depended on whether this was a problem/ issue that had been previously well-researched or a new/relatively un-/under researched one. Once Question (a) had been answered, then Question (b) could be. In relation to Question (a) a literature search indicated little was known about the issue of destination quality from the tourists' perspective, this was a new topic and hence the research was regarded as exploratory. As there was no known pre-existing literature on the issue, an attempt to gain insights into and a clearer understanding of it, would require results to be in depth and detail, it was decided. However, the intention of the research was not to just gain depth and detail, which would almost certainly mean obtaining views from a relatively small number of tourists, but also to gain a broader understanding from a larger population of tourists.

Therefore, in relation to Question (a) above, attempting to gain depth and detail concerning the issue, but also a wider understanding of it, had implications for the conduct of the research, specifically in terms of the nature of the underlying philosophy and the data collection techniques to be used. It was clear from what was required, that two philosophical and practical approaches to conducting the research would be required, but also that they would need to be sequenced. Therefore, of particular importance, in terms of the practicalities of actually doing the research, a decision on how the two approaches would be sequenced was required. Figure 1 shows the questions in chronological order that were created once the two initial questions, (a) and (b) above, were answered. This article discusses responses to Questions 1-14, as these are the key methodology questions. 
1) What research philosophy should be used in the first phase of research?

2) Which research techniques should be used in the first phase of research?

3) What specific questions should be asked in the first phase of research?

4) How should pre-testing take place in the first phase of research?

5) How should a pilot study be created and used in the first phase of research?

6) How should the results of the pilot study be used to help design the main research instrument in the first phase of research?

7) How should the research in the first phase be conducted?

8) How should results of the first phase of research be used in the second stage?

9) Which research philosophy should be used in the second phase?

10) Which research techniques should be used in the second phase?

11) What specific questions should be asked in the second phase?

12) How should a pilot study be created and used in the second phase?

13) How should the second stage research be conducted?

14) How should the results from the second stage be analysed?

15) What were the overall findings of Phase 1 and Phase 2?

16) What conclusions could be drawn from the findings?

17) What recommendations (if any) could be made, based on the findings?

Figure 1. Sequential research questions in the TDQ study

Source: based on Seakhoa-King et al. [2021].

In relation to Question 1 in Fig. 1, what research philosophy would be appropriate for use in the first phase, a literature search had indicated little was known about the issue of what tourism destination quality is from the tourists' perspective, and hence the research was regarded as exploratory [Stebbins 2001; Cresswell 2009]. As far as was known there was no pre-existing literature on the topic, so any attempt to gain insights into this unexplored issue, would require results to be in depth and detail, it was decided. However, the intention of the research was not to just gain depth and detail, which would almost certainly mean obtaining views from a relatively small number of tourists, but also to gain a broader understanding from a larger population of respondents. Attempting to gain depth and detail, but also a wider understanding of the issue, had implications for the conduct of the research in terms of the nature of the underlying philosophy and the data collection techniques to be used [Teddlie, Tashakkori 2009]. However, once it was clear that two approaches to conducting the research would be required, of particular importance, in terms of the practicalities of actually doing the research, was deciding how it would be the sequenced.

The choice of the research philosophy in the first phase of research was primarily guided by the nature of the problem to be researched [Mason et al 2010]. Given that the detailed and in-depth views of tourists were required 
for the initial part of the research, the philosophy of interpretivism was regarded as appropriate and this underpinned the first phase.

To briefly outline the meaning of later questions (Questions 9-17) in Fig. 1, having conducted the research in response to Questions 3-8, the second phase of the research could then begin with an answer to Question 9, and proceed through, in sequence, up to Question 14, prior to a consideration of the entire research process in terms of overall analysis, conclusions and recommendations (if required) (see Questions 15 to 17 in Fig. 1).

\section{The TDQ Study: Designing the Qualitative Phase of Research}

The design of the qualitative phase of the TDQ studies followed several stages, which are discussed sequentially in sections 4.1-4.6.

\subsection{Selecting Qualitative Data Gathering Techniques}

In response to Question 2 in Fig.1, in terms of how this initial phase should be conducted, with exploratory studies much literature suggests that the qualitative research approach is appropriate [see e.g. Patton 1990; Sekaran, Bougie 2016]. Hence, qualitative methods were regarded as most suitable in this initial phase, and it was considered appropriate to use qualitative techniques to capture individual tourists' views on their understanding of tourism destination quality [Maykut, Morehouse 1994; Patton 2014]. Once Question 2 in Fig. 1 had been answered, then it was possible to consider subsequent questions (Questions 3-8 in Figure 1) and how responses would be achieved.

However, to return to the first stage of the planned research, it is accepted that qualitative research can have flexible research design, where researchers have freedom to experiment, before establishing the most appropriate technique(s) for the study [Bernard 2000]. Therefore, in an attempt to answer Question 2 in Fig. 1, it was necessary to ascertain which techniques would be most appropriate. As a starting point, previous exploratory studies [Minjoon, Peterson, Zsidisin 1998; Echtner, Ritchie 1991; 1993] were reviewed, leading to the identification of three possibilities: an openended questionnaire, an in-depth interview, and a focus group interview. These three techniques are also recommended by several other researchers [Finn, Elliott-White, Walton 2000, Frankfort-Nachmias, Nachmias 2008; Krueger 1994] in this type of context and each is discussed briefly below.

An open-ended questionnaire is a technique where respondents are required to answer questions in their own words, rather than in pre-determined categories [Finn et al. 2000; Frankfort-Nachmias, Nachmias 2008]. 
An advantage of an open-ended questionnaire is that respondents can be asked to complete it themselves, unaided by a researcher [Frankfort-Nachmias, Nachmias 2008], which can eliminate researcher biases to which other qualitative data gathering techniques can be prone [Berg 1995]. However, a disadvantage is that open-ended questionnaires may be very time-consuming to complete [Frankfort-Nachmias, Nachmias 2008].

A focus group is a planned group discussion intended to obtain participants' views on a topic [Krueger 1994]. The participants for focus groups are selected on the basis that they share certain characteristics relevant to the research issue but have not previously been in contact [Bernard 2000; Krueger 1994]. Full agreement on the size of a focus group is lacking, but somewhere between 6 and 12 is usually considered appropriate [Marshall, Rossman 2014; Sekaran, Bougie 2016]. However, focus groups consisting of fewer than five and larger than twelve participants are frequently reported in literature [Marshall, Rossman 2014].

The advantages associated with the technique, are that it is able to generate a good deal of information, particularly when participants 'spark each other off' [Berg 1995; Morgan 2006], and its relatively flexible nature provides the freedom to explore unanticipated issues that may arise [Krueger 1994]. Furthermore, as there are more participants in focus groups than in much qualitative research, this can overcome issues of small sample size, as well as save time [Morgan 2006].

However, a major weakness of this technique is that it can be prone to bias, particularly if researchers lead participants to say what they think the researcher wants to hear [Kruger 1994; Morgan 2006]. This technique can create false consensus wherein participants with strong personalities and / or similar views may dominate the discussion, while others may remain silent [Kruger 1994]. A researcher will have less control when gathering data, than in the context of an interview, meaning focus groups can be time-wasting, as irrelevant issues are discussed [Morgan 2006].

There are various definitions of the in-depth-interview. However, N. Lincoln and E. Guba [1985] indicate that it is a purposeful conversation, and R. Bodgan and S. Biklen [1982] concur, adding it usually between two people. The term 'in-depth' here means to go into detail and to get more understanding of a topic [Wengraf 2001]. This technique can maximise the amount and variety of information obtainable from each interviewee [Wengraf 2001]. It also has the advantage that trust can be built, making it possible to gain information that would not be obtained otherwise [Adams, Schvaneveldt 1991].

A major disadvantage is that the technique can be time consuming [Jennings 2011; Wengraf 2001]. Bias, arising from the verbal and non-verbal actions and reactions of the interviewer can also be a problem [Frankfort-Nachmias, Nachmias 2008; Jordan, Gibson 2004]. 
The next section outlines the process of constructing each of the three data collection techniques adopted in the first phase of the research process.

\subsection{Designing Qualitative Data Gathering Techniques}

The process of designing the data collection techniques commenced with the formulation of questions (see Question 3 in Fig. 1). This is crucial, as the nature and quality of the questions have significant effects on the overall research findings, and the relevance of information collected depends on the questions [Belson 1986; Foddy 1993]. As there is a risk that questions containing errors can be incorporated in data collection instruments [de Vaus 2013], preventative measures to reduce risk were incorporated in the design. Literature provides strategies for reducing the risk of formulating questions with errors [e.g. Foddy 1993; Sudman, Bradburn 1982] and these consisted of five steps.

- Step one: determine precisely what information is needed. A major source of what information is required is the research question/research aim (s) [Foddy 1993; Sudman, Bradburn 1982] and reading and re-reading this was the approach used in the TDQ study.

- Step two: decide on questioning strategy. Generally, the choices are whether to use open-ended or closed-ended questions, or possibly both [Oppenheim 1992]. As open-ended questions are more suited for qualitative studies [Patton 2014], this strategy was selected. However, it was decided that some questions in this first phase would be closed-ended, to identify the socio-economic and travel characteristics of respondents [Frankfort-Nachmias, Nachmias 2008].

- Step three: formulate suitable questions. The questions formulation process resulted in

a) five open-ended questions concerned with tourism destination quality, and

b) six closed-ended questions, plus two open-ended questions, concerned with socio-economic and travel characteristics.

- Steps four and five: pre-tests, revising and confirming the questions. Generally, it is suggested questions should be pre-tested [Foddy 1993], to detect any errors [Foddy 1993; Zikmund, Carr, Griffin 2013]. To enable 'pre-testing' of the questions, a questionnaire divided into Sections A and B was developed, where Section A consisted of the five open-ended questions concerned with tourism destination quality, and Section B comprised six closed questions and the two open-ended questions to gather respondents' profile.

Pre-testing of questions (see Question 4 in Fig. 1) is usually conducted with small numbers of respondents drawn from the target population [Foddy 1993; Belson 1986; Zikmund et al 2013]. However, in the TDQ study, a pre- 
liminary step was added that involved pre-testing using students from the researchers' University Business School. This led to the elimination of some minor errors prior to the main pre-test of questions conducted with a sample of tourists at a UK shopping mall and twenty questionnaires were distributed. Each questionnaire was completed in the presence of the researcher, with respondents being encouraged to comment on the quality of questions, to help make improvements [see Belson 1986]. Based on the respondents' comments, changes were made to the wording of some questions in Section A, resulting in six open-ended questions. The six closed-ended questions and two openended questions in Section B did not require any changes.

The second stage in the designing of the techniques involved the construction and pre-testing of each of the three techniques. Using the questions trialled in the pre-test, first the open-ended questionnaire was developed, following guidelines particularly from A.N. Oppenheim (1992] and A.J. Veal [2011]. The resulting questionnaire consisted of Section A, made up of six open-ended questions concerned with destination quality, and Section B comprised six closed-ended questions and two open-ended questions concerned with the respondent's profile.

Regarding the in-depth interviews and the focus group interviews, it was decided to use the same questions as used in the open-ended questionnaire to enable comparisons to be made, and separate pre-tests were conducted for each technique, using five respondents, and no problems emerged.

Pre-testing of the focus group interview was conducted with eight University Business School students who had had no previous involvement in the research. The problems that occurred were respondents often spoke to two or three people at the same time, which created a problem when transcribing, and some respondents spoke quietly, so could not be heard well. Improvements were then made for the planned pilot study.

\subsection{Piloting Qualitative Research Techniques}

It was difficult to anticipate whether the three techniques would work in the TDQ study, and as D.G. Miller [1991] noted, techniques of data collection are useful if (and only if) they are appropriate within the context of the study in which they are employed. As a result, it was decided to conduct a pilot study, to try out the suitability of each. For this to be meaningful, criteria for assessing the suitability of each collection techniques were established in advance [see Mason et al., 2010; Patton 2014; Seakhoa-King et al., 2021]. These criteria were: (1) effectiveness, (2) efficiency, (3) depth and detail, and (4) the uniqueness of data generated.

Effectiveness of data collection techniques was assessed in terms of the technique's ability to generate required data, while efficiency was assessed 
in terms of the amount of data each technique could generate per respondent [Patton 2014; Seakhoa-King et al., 2021]. Regarding depth and detail, each technique was assessed in terms of the meaningfulness of data [Patton 2014]. Uniqueness of the data was assessed in terms of the ability of a technique to generate information no other technique generated [Patton 2014; Seakhoa-King et al 2021].

A detailed plan of the pilot phase of the TDQ study was created (see Question 5 in Fig.1) with the intention of involving a relatively large number and variety of participants, spread across several different locations. This sample was intended to gain a deep and detailed understanding of tourists' understanding of destination quality and the type of sampling used was purposive [Mason 2014; Patton 2014]. This means that the selection of subjects ensured that 'information rich' [Patton 2014] individuals were included - i.e. those with the potential to provide the greatest insights into the research questions [Devers, Frankel 2000].

'Information rich' subjects are usually identified against criteria relevant to the study, pre-determined by the researcher [Patton 2014]. As tourists from different backgrounds could have different views on destination quality, respondents from diverse demographic origins were to be included. As a result, socio-demographic and travel characteristics were the pre-determined criteria for selecting respondents. Data was then collected in locations in England and South Africa, as part of a strategy of triangulation of locations of data collection [Decrop 1999]. This was intended to ensure that potential differences in views, based on different locations, were captured. The places were chosen by means of convenience sampling [Henry 1990], but in the case of South Africa, one of the team of researchers was co-incidentally visiting the country.

There were some issues in relation to the piloting of each technique. In terms of the open-ended questionnaire, not all respondents understood the questions concerned with destination quality and the questionnaire was improved and four new open-ended questions created and then pre-tested at a UK shopping centre, before being successfully piloted at Stansted Airport with a sample of 40 respondents completing the questionnaire.

The piloting of the in-depth interviews was conducted after the completion of the open-ended questionnaires, using convenience sampling. This sequence enabled the questions developed previously to be used for the indepth interviews [Patton 2014]. The same location was used for the piloting of the open-ended questionnaire. The major issues in this case were related to recording techniques. Initially, manual written recording was conducted, but this took too long, and subsequently an electronic recorder was used, but some respondents were not happy with this. Additionally, interviewing in public spaces led to problems, as this setting was uncomfortable for some participants. In terms of the piloting of the focus group, no major issues occurred. 
The data gathered in the pilot study of all three techniques was analysed using the constant comparison technique developed by B. Glaser and A.L. Strauss [1967]. Constant comparison is a process whereby data is coded into emerging themes and then repeatedly revised until it is apparent that no new themes are emerging, and the themes are then categorised (this process is discussed in more detail in section 4.6). The analysis of pilot study data enabled the assessment of the suitability of each three data gathering techniques.

\subsection{Learning from Qualitative Pilot Study Results}

A total of 92 respondents, spread over the three techniques, were involved in the pilot and there was a wide range of characteristics. There was an almost equal proportion of male and female respondents, all ages from 18 to $55+$ were well represented, a range of different income levels from low to high took part, education of respondents ranged from just post-primary up to postgraduate levels, and just under a half of the sample had travelled with children.

The suitability of each technique was assessed based on the four criteria discussed in Section 4.3: (1) effectiveness, (2) efficiency, (3) depth and detail, and (4) the uniqueness of data generated. While the data generated by each data collection technique was evaluated separately, the results of the pilot study conducted in various places have been combined, since there were no significant differences in the results from different data gathering locations.

The effectiveness of each data collection technique was assessed in terms of whether it could generate the type of data that was required. The amount of relevant data was measured in terms of the number of units of meaning [Maykut, Morehouse 2002]. The results indicated each data collection technique produced some relevant data. However, the largest amount, 104 units of meaning, was obtained from in-depth interview data, whilst the focus group produced 10 units of meaning and the open-ended questionnaire 56. The results indicate that the in-depth interview technique was the most effective technique employed.

The efficiency of the techniques was assessed in terms of the amount of data that each technique could generate, divided by the number of respondents involved with each. The in-depth interview technique generated an average of 9.45 (104/11) units of meaning per respondent, while the focus group interviews generated only 1.10 (11/10) units of meaning per respondent and the open-ended questionnaires produced just $0.79(56 / 71)$ units of meaning per respondent. Therefore, the in-depth interview technique was the most efficient technique employed.

The depth and detail of the data generated by each technique was assessed in terms of the meaningfulness of data. The results of the pilot study indicated that in-depth interviews generate more in-depth and detailed data than focus group interviews and open-ended questionnaires. 
The uniqueness of the data generated was assessed in terms of the ability of each technique to generate data that no other had generated. A comparison of the units of meaning generated by each technique indicated that the in-depth interviews were the source of most unique data.

A summary of the results of the evaluation of the pilot study data is presented in Table 1, and this indicates the superiority of the in-depth interview, which can be attributed to some of the strengths inherent in this technique. In particular this relates to the use of probes that can be used to get explanation of answers from interviewees [Bernard 2000], which is not possible with the open-ended questionnaire technique. Also, probes can mean respondents add depth and detail to answers [Mason et al 2010; Patton 2014] and can be used to raise related points, thereby improving the overall efficiency and effectiveness of this technique.

Table 1. Comparison of the Usefulness of Data Collection Techniques in the TDQ Pilot Study

\begin{tabular}{|l|l|l|l|l|}
\hline \multirow{2}{*}{\multicolumn{1}{|c|}{ Techniques }} & \multicolumn{4}{c|}{ Criteria for Assessing the Data Collection Techniques* } \\
\cline { 2 - 5 } & Effectiveness & Depth and Detail & Efficiency & Uniqueness \\
\hline In-depth Interview & $\checkmark$ & $\checkmark$ & $\checkmark$ & $\checkmark$ \\
\hline Focus group & $\checkmark$ & $\checkmark$ & & \\
\hline Open-ended questionnaires & $\checkmark$ & & & \\
\hline
\end{tabular}

Source: [Seakhoa-King et al 2021].

Pilot study data was also used to evaluate the potential usefulness of the open-ended questions designed for the qualitative phase of the TDQ study. Each of the open-ended questions was analysed in terms of the total number of units of meaning per question to determine the most suitable questions to be used in the planned exploratory study. Two questions that generated the highest number of units of meaning: 'In your own opinion, what are the characteristics of a quality tourism destination?' and 'In your own opinion, what makes a quality tourism destination?' were selected to be used in the first phase of the qualitative exploratory TDQ study.

The pilot study had several implications for the design of the planned qualitative phase. In relation to the site for conducting the study, the pilot study revealed that the site of data collection, had little, if any, impact on the results. Hence, collecting data at multi-sites would not be necessary. It also indicated that the site chosen should be a place frequented by a wide spectrum of tourists, in terms of e.g. ethnicity, gender and age group backgrounds, but also where there were no distracted e.g. shopping.

Concerning the choice of data collection techniques, the in-depth interview was found to be the most appropriate technique in the pilot study, and it was decided that this would be employed for the main qualitative phase of the TDQ study. 
Regarding the choice of questions to be used, the questions: 'In your own opinion, what are the characteristics of a quality tourism destination?', and 'In your own opinion, what makes a quality tourism destination?' showed the most potential to generate the data required.

As for the research strategy for recording responses to be used, the pilot revealed that each recording technique had advantages and disadvantages. The implications for the exploratory study were that both techniques could be employed, to make use of the advantages of each. This meant the interviews would be recorded and notes would also be taken.

\subsection{Designing Sampling and Interviewing Procedures for the Qual- itative Research}

Given the results of the pilot study, it was decided that the in-depth interviews would be conducted between July and August at Trafalgar Square, in London, an attraction visited by a wide spectrum of tourists and where activities were not likely to discourage tourists from participating.

The sampling frame was composed of tourists who were present at Trafalgar Square during the period of data collection. Although sample sizes of between 15 to 40 have been proposed as adequate [de Ruyter, Scholl 1998], consensus on the number of interviews in qualitative research is yet to be reached. A strategy for determining an appropriate sample size, suggested by B. Glaser and A.L. Strauss [1967], known as theoretical sampling, was employed. The researcher continued interviewing until a point of 'saturation' was attained, i.e. when no new information was being obtained [Glaser, Strauss 1967], which in the TDQ study was when 41 interviews had been conducted.

The procedures for selecting respondents for the qualitative exploratory phase of the TDQ study, and for interviewing, were similar to those used in the pilot study. The formal interviewing process began with the researcher asking the question: 'In your own opinion, what are the characteristics of a quality tourism destination?'. Once the discussion was underway, the researcher relied mainly on the use of probes to stimulate further discussion and asked the remaining questions. Interviews were completed with the question 'Are there any other points you can think of?' [Bernard 2000; Ryan 2000]. All interviews were electronically recorded.

\subsection{Selecting Techniques for Analysing the Qualitative Research Results}

Given the exploratory nature of the research, the approach to analysing the qualitative data was to 'let the data speak for itself' [Jordan and Gibson 2004], which means results are grounded in the data. Since the constant 
comparison method [Glaser, Strauss 1967] that had been used in the pilot study proved to be suitable, it was employed to analyse the TDQ study's in-depth interview data. There were five major steps involved in analysing data using the constant comparison method [Maykut, Morehouse 1994].

Step one: preparing the interview data for analysis. The in-depth interviews were transcribed, and the transcripts labelled. After labelling, the transcripts were photocopied and the original transcripts stored for safekeeping, to ensure the original material was not lost. Photocopies of the transcripts were then used in subsequent stages of data analysis.

Step two: unitising the interview data. The next step was to unitise the data [Maykut, Morehouse 1994]. This is the process of searching for meaning through identifying '....chunks or units of meaning in the data' [Maykut, Morehouse 1994, p. 127]. In the initial stages, small units of meaning were identified, and these would then form the '...basis for defining larger categories of meaning' [Maykut, Morehouse 1994, p. 127]. This led to a total of 175 unitised index cards.

Step three: developing and assigning units of meaning to provisional categories. All 175 unitised index cards were pasted to a wall. The first higher-level category was developed in vivo (i.e. from the data itself) by randomly selecting a unitised index card and by assigning a name to the category that conveyed a wider sense of the unit of meaning presented on the unitised index card. The name of the category was written on a blank category index card. The unitised index card was placed under the category index card. If subsequent index cards did not fit the existing higher-level category, a new one was created. This process continued until all 175 index cards had been checked.

Step four: transforming the units of meaning to attributes. An index card consisting of a unit of meaning belonging to a specific category was selected. Using wording as close as possible to that in the unit of meaning, the first attribute of tourism destination quality for that particular category was created. To develop a second attribute, a second unit of meaning from the same category as the first unit of meaning, was selected to formulate the second attribute, and entered under the category where it belonged. This process was repeated until all the index cards falling within a given category had been exhausted, before moving on to the next category. This process then resulted in an initial list of attributes that were then allocated to respective categories (dimensions) of tourism destination quality.

Step five: refining the categories and attributes. Two tourism academics, not connected to the study, were asked to: (a) critique the categories and attributes developed, and (b) suggest the categories or attributes which could be further merged to try to eliminate duplicates [Echtner, Ritchie 1993]. Involving researchers to critique, comment or make suggestions during qualitative data analysis, is a widely employed strategy [e.g. Echtner, 
Ritchie 1993] to bring external scrutiny to the process, thus enhancing the validity of the outcomes [Perreault, Leigh 1989; Sinkovics, Penz, Ghauri 2005].

Subsequently, on the basis of the two experts' comments, some categories and attributes were merged and then a revised list of the categories and attributes of tourism destination quality was produced. The revised list of attributes was shown to experts again for comment. This process was then repeated. At each stage of this process, the researcher discussed with the experts the changes they were recommending. The final result was a list of 75 attributes, linked to 12 dimensions of destination quality, which were then used to inform the second (quantitative) stage of the TDQ study (see Question 9 in Fig.1).

\section{The TDQ Study: Designing the Quantitative Phase of the Research}

The use of quantitative research in the second phase of the TDQ study provided an opportunity for findings from the qualitative phase to be assessed, using a larger, more representative sample of the population of tourists. Also, a quantitative approach would enable an assessment of whether there were any significant differences in responses among tourists, based on their socio-economic and travel characteristics. Therefore, a quantitative survey research approach was adopted (see Question 10 in Fig.1), which involved collecting data about respondents' characteristics, experiences, and opinions [Frankfort-Nachmias, Nachmias 2008].

A self-administered (or self-completion) questionnaire technique [Bernard 2000] was employed in this phase (see Question 10 in Fig.1), as this type of questionnaire has certain strengths in that respondents give answers without the help of a researcher [Frankfort-Nachmias, Nachmias 2008]. This has the advantage of reducing the researcher's bias [Oppenheim 1992]. In addition, this technique is regarded as appropriate where a researcher intends to ask a relatively large number of questions [Bernard 2000], which was the case in this phase of the TDQ study. In addition, with this technique, the researcher can use questions that are difficult to ask using other methods [Bernard 2000]. For example, spoken questions involving a list of response categories, e.g. such as a Likert scale, can be difficult for respondents to follow (Bernard 2000). However, disadvantages associated with this technique include misinterpretation of questions by respondents [Oppenheim 1992]. The commonly used strategy for identifying and rectifying questions that could be misinterpreted, involves subjecting the questionnaire to pilot testing [de Vaus 2013]. Hence, this strategy was employed in the TDQ study. 


\subsection{Designing the Quantitative Self-administered Questionnaire}

The design of the quantitative self-administered questionnaire followed a systematic process involving four steps [de Vaus 2013].

Step one: development of questions. Tourists' opinions provided and analysed in the qualitative phase of the TDQ study were used to develop questions for the self-administered questionnaire (see Question 11 in Fig. 1). Specifically, each of the 75 attributes identified in the qualitative phase was converted into a scale item, which is a statement designed to allow respondents to give their opinion [Oppenheim 1992; de Vaus 2013]. The intention was to enable respondents to provide their opinion on each attribute and this required a measurement scale. The most widely scales used are the Likert, Guttman and Thurstone Scales [Judd, Smith, Kidder 1991]. In the TDQ study, it was decided to adopt the Likert-scale as this is considered to be more reliable than others, respondents find it easier to use than the Guttman and Thurstone Scales [Judd et al.1991], and it can be used to measure multi-dimensional constructs (such as quality), unlike Guttman and Thurstone scales [Judd et al., 1991]. A seven-point Likert-type rating scale was employed, as this is considered to facilitate better discrimination of responses than other interval scales [Ryan 1995]. The scale used intervals ranging from $1=$ Strongly Disagree to $7=$ Strongly Agree, although no labels were used for the numbers between 1 and 7. In line with a number of researchers [e.g. Moser, Kalton 1975; Ryan 1995], an option of 'No Opinion', denoted by a zero (0), was also provided for respondents that did not have an opinion.

Step two: draft design of the self-administered questionnaire. A draft version of the questionnaire, comprising Sections A and B, was then developed. Section A contained 75 scale items based on the findings of the qualitative phase, and respondent opinions were to be provided on the sevenpoint Likert scale. Section B comprised questions concerned with respondents' demographic and socio-economic profile.

Step three: pilot test of the self-administered questionnaire. The draft version of the questionnaire was piloted at Stansted Airport (see Question 12 in Fig.1) mainly because this was a lengthy, self-administered questionnaires, which could be prone to a low response rate. Hence, the site of an airport was selected to ensure it was suitable for a relatively long questionnaire. An airport was also considered as appropriate, as it offered a potential pool of 'captive' respondents [Echtner, Ritchie 1993] with time to complete the questionnaire.

The pilot study was conducted in the lounge areas of the main terminal buildings of Stansted Airport, and respondents were informed that it was a pilot test [de Vaus 2013]. Declaring the pilot test had been used successfully at the qualitative phase, so was repeated here. 
Examination of the completed piloted version of the questionnaire, revealed areas requiring further improvement, specifically relating to respondents giving many high scores (six or seven on the scale) to questions in Section A. This is termed 'acquiescence bias' and is not uncommon. Another area of improvement was related to font size, which some respondents felt was too small to read. It was therefore decided to conduct a second pilot test in an attempt to rectify these problems. As 'acquiescence bias' can be caused by the sequencing of questions [Frankfort-Nachmias, Nachmias 2008], those in Section A were revised, resulting in random question presentation, in an attempt to reduce this bias.

The second stage of the pilot test was intended to be a complete simulation of the actual main fieldwork and was therefore undeclared [de Vaus 2013]. In total, 50 questionnaires were distributed to tourists at Luton Airport and 50 questionnaires at Stansted Airports and all questionnaires were returned, completed.

The data from the pilot test was analysed using the Statistical Package for the Social Sciences (SPSS) for Windows, which provided an opportunity to create a plan for data analysis, i.e. to devise a coding scheme and make decisions on data analysis techniques ahead of the main fieldwork of the quantitative phase [see Saunders et al., 2009].

Step four: final design of the self-administered questionnaire. Modifications in earlier stages of the pilot study showed that there were no longer problems with the questionnaire, which meant that it could be employed in the main quantitative phase of the TDQ study.

\subsection{Designing Sampling Procedures for the Quantitative Research}

As with the pilot study, Luton and Stansted Airports were selected as sites for data collection in the quantitative phase of the TDQ study due to the length of the questionnaire (see Question 13 in Fig.1). Of significance also was that an airport offered a 'neutral' location - it was not an actual tourism destination, thereby avoided contextualising the study. Before collecting data, the researcher contacted the management of both airports in writing, seeking and gaining permission to conduct the research.

The population for the quantitative phase of the TDQ study was tourists selected by convenience sampling [Patton 2014], involving people at the airports at the time the study was conducted. Data collection was between 9 am and $4 \mathrm{pm}$ (Monday-Sunday) for a period of one week.

In terms of sample size, studies of this type usually restrict themselves to no more than 200 respondents, but this brings into question the reliability and the validity of results [Kozak 2000]. Literature indicates a positive relationship between the number of scale items and the sample size, suggesting a ratio of at least 1:4 [Tinsley, Tinsley 1987] or more acceptably 1:10 
[Hair, Black, Babin, Anderson 2014; Nunnally 1967]. Given that there were 75 scale items in the questionnaire, the target sample was 750 questionnaires i.e. ten times the number of scale items.

\subsection{Selecting Techniques for Analysing the Quantitative Research Results}

Descriptive data analytical techniques using SPSS for Windows were employed to indicate which attributes and dimensions tourists most strongly associated with tourism destination quality (see Question 14 in Fig.1). The most commonly used descriptive statistics, mean and standard deviation scores [Cooper, Schindler 2018; Sekaran, Bougie 2016], were calculated for each attribute and dimension, and they were then ranked in a descending order, based on mean scores values. The mean score values were interpreted as follows: the lower the mean score, the less tourists were considered to associate that particular attribute, or dimension, with destination quality, whilst the higher the mean score, the greater the extent to which tourists were considered to associate the attribute, or dimension with destination quality.

Statistical data analytical techniques for comparing groups were employed to investigate a number of hypotheses that had been established to investigate relationships between dependent and independent variables. Here, the dependent variable was what tourists associated with tourism destination quality (represented by the twelve dimensions), while the independent variables were the tourist demographic factors such as age, gender and education level.

The main goal for investigating these hypotheses was to establish whether there were any significant differences in tourists' responses based on their socio-economic and travel characteristics. Two types of statistical data analytical techniques for comparing groups were used. They were: (a) tests to establish whether groups were significantly different, and (b) tests to ascertain the strength of association between the dependent and independent variable.

Both major types of statistical tests, namely parametric and non-parametric tests were used [Zikmund, et al., 2013]. Parametric tests are regarded as more powerful than non-parametric tests [Tabachnick, Fidell 2007] as they are more sensitive in detecting a relationship or difference between groups than non-parametric tests [Tabachnick, Fidell 2007]. For this reason, it is usually recommended that parametric tests should be used, where possible [Tabachnick, Fidell 2007]. However, parametric tests usually require data that is to be analysed to meet certain stringent assumptions in terms of: independence of observations; the sample coming from a normally distributed population; the sample coming from a population of equal variance; and that the measurement scales used to collect data are interval 
scales [Cooper, Schindler 2018; Zikmund et al., 2013]. The main reason for using both types of test is that there is debate about whether self-administered questionnaires using a Likert scale, meet the requirements of parametric tests, as some researchers argue Likert scales are 'ordinal' whilst others that they are 'interval' [Pallant 2013; Sekaran, Bougie 2016]. Given the significant amount of controversy, where possible both parametric and non-parametric tests were employed. The use of both parametric and nonparametric techniques can also be viewed a part of a strategy of triangulation of methods. Parametric tests were the primary statistical techniques on which the interpretation of the results of this phase were based.

Depending on the hypothesis being investigated, the following tests were used to establish whether groups were significantly different: t-test for independent samples, the Mann-Whitney U test, the one-way betweengroups Analysis of Variance (ANOVA) and the Kruskal Wallis test.

The t-test and the ANOVA test, referred to above, can only reveal whether group differences are statistically significant. They do not provide any indication as to the magnitude of the difference [Cohen 2013]. Such information is particularly important given that small differences can be statistically significant, especially where relatively large samples are involved [Tabachnick, Fidel 1996]. According to J. Pallant [2013], although small differences can be statistically significant, they may have no practical or theoretical value. Consequently, where t-tests and ANOVA tests detect statistically significant differences, it is necessary to conduct additional tests to assess the meaningfulness of such differences [Cohen 2013].

One way of assessing the meaningfulness of statistically significant findings is to calculate the 'effect size' [Cohen 2013; Tabachnick, Fidel 1996]. This is a set of statistics which indicate the relative magnitude of the differences between mean score values. There are a number of different 'effect size' statistics that can be computed. In the TDQ study one of the most frequently used 'effect size' statistic, eta squared [Cohen 2013], was employed to ascertain the strength of association between the dependent and independent variables.

\section{Conclusions}

This article has discussed the methodology employed in the TDQ study, revealing a sequential mixed method research process, which involved a qualitative phase that explored what tourists associate with tourism destination quality, followed by a quantitative phase that examined whether the emergent results could be generalized to the whole study population. Hence, this methodology can be seen to fit within J.W. Cresswell's [2009] sixfold typology, under the sub-heading of sequential research, and more precisely can be termed exploratory sequential research. 
Although the overall findings have not been discussed in this article, they indicated that the results obtained in the qualitative phase were strongly backed up by the outcomes of the quantitative phase, providing significant evidence for the successful use of mixed methods in the TDQ study [for an indepth discussion of the results, see Seakhoa-King et al., 2021]. The article has demonstrated that an initial systematic qualitative phase of research can be used within an overall mixed methods research approach to precede a quantitative phase. Such an approach generated robust and rigorous research findings. This supports the claim of A. Teddlie and A. Tashakkori [2009] that mixed methods research is primarily focused on 'what works', and less concerned with arguments about different philosophical positions.

Additionally, the results of the qualitative pilot study data indicate the superiority of the in-depth interviews technique over focus group interviews and open-ended questionnaires in terms of the technique's effectiveness, efficiency, and ability to generate in-depth, detailed and unique data. Similar findings, concerning the superiority of in-depth interviews in other fields, particularly marketing, have been revealed, when different qualitative techniques have been compared [see for example, George, 2010 and Granot, Brasher, Motta 2012]. This is an important finding for future researchers considering alternative qualitative data gathering methods, as well assisting those engaged in types of similar mixed methods research.

This article provides confirmation of the growing use of mixed methods in the social sciences and specifically in tourism [see Khoo-Lattimore et al., 2019; Timans, et al., 2019], and it advances knowledge of the effectiveness of mixed method methodologies and techniques in the field. The original aim was to indicate how the research was conducted and it was not intended to be prescriptive, but by providing a detailed account of a systematic sequential mixed method approach, the paper may, it is hoped, provide a blueprint for researchers who are intent on conducting similar research.

\section{References}

Adams G.R., Schvaneveldt J.D. (1991), Understanding Research Methods $\left(2^{\text {nd }}\right.$ ed.), Longman, New York.

Belson W.A. (1986), Validity in Survey Research, Gower Publishing Company, London.

Berg B.L. (1995), Qualitative Research Methods for Social Science (2nd ed.), Allyn and Bacon, London.

Bernard H.R. (2000), Social Research Methods: Qualitative and Quantitative Approaches, Sage, Thousand Oaks, London.

Bogdan R., Biklen S. (1982), Qualitative Research for Education: Introduction to theory and methods, Allyn and Bacon, Boston. 
Cohen E. (1972), Toward a sociology of international tourism, "Social Research", Vol. 39, pp.164-182.

Cohen J. (1988), Statistical Power Analysis for the Behavioural Sciences, Erlbaum Hillsdale, NJ.

Cohen L. (2013), Research Methods in Education, ( $7^{\text {th }}$ ed.), Routledge, London.

Cresswell J.W. (2009), Research Design: Qualitative and Quantitative Approaches, ( $3^{\text {rd }}$ ed.), SAGE, Thousand Oaks, California

Cresswell J.W. (2018), Research Design: Qualitative and Quantitative Approaches, (5 $5^{\text {th }}$ ed.), SAGE, Thousand Oaks, California.

Cresswell J.W., Plano Clark V., (2003) Designing and conducting mixed methods research, SAGE, Thousand Oaks, CA

Cresswell J.W., Plano Clark V., Gutman M., Hanson W. (2003), Adnaced mixed methods design [in:] Tashakkori and Teddlie (Eds), A Handbook of Mixed Methods Research in the Social and Behavioural Sciences, SAGE, Thousand Oaks. CA, pp209-240.

Dann G. (1977), Anomie, ego-enhancement and tourism, "Annals of Tourism Research", Vol. 4, pp. 184-194.

Davies B. (2003), The role of quantitative and qualitative research in industrial studies of tourism, "International Journal of Tourism Research", Vol. 5, pp. 97-111.

de Ruyter K., Scholl N. (1998), Positioning qualitative market research: Reflections from theory and practice, "Qualitative Market Research: An International Journal", Vol. 1, pp. 7-14.

de Vaus D.A. (2013), Surveys in Social Research, Taylor and Francis, London.

Decrop A. (1999), Triangulation in qualitative tourism research, "Tourism Management", Vol. 20, pp. 157-161.

Devers K.L., Frankel R.M. (2000), Study design in qualitative research-2: Sampling and data collection strategies, "Education for Health: Change in Training and Practice", Vol. 13, pp. 263-271.

Echtner C.M., Ritchie, J.B.R. (1991), The meaning and measurement of destination image, "Journal of Tourism Studies", Vol. 2 (2), pp. 2-12.

Echtner C.M., Ritchie, J.B.R. (1993), The measurement of destination image: An empirical assessment, "Journal of Travel Research", Vol. 31 (4), pp. 3-13.

Eldabi T., Irani Z., Paul R.J., Love, P.E. (2002), Quantitative and qualitative decision-making methods in simulation modelling, "Management Decision", Vol. 40, pp. 64-73.

Finn M., Elliott-White M., Walton M. (2000), Tourism and Leisure Research Methods: Data Collection, Analysis and Interpretation, Pearson Education Ltd, Essex, England.

Foddy F. (1993), Constructing Questions for Interviews and Questionnaires: Theory and Practice in Social Research, Cambridge University Press, Cambridge. 
Frankfort-Nachmias C., Nachmias D. (1996), Research Methods in the Social Sciences, (5 ${ }^{\text {th }}$ ed.), St. Martin's Press, New York.

Frankfort-Nachmias C., Nachmias, D. (2008), Research Methods in the Social Sciences, (7 ${ }^{\text {th }}$ ed.), St. Martin's Press, New York.

George R. (2010), Nine reasons to use in-depth interviews, Online: https:// rmsresults.com/2010/07/20/in-depth-interviews-market-research-inupstate-ny-central-new-york-syracuse-survey/; accessed December $7^{\text {th }}$, 2020.

Glaser B., Strauss A.L. (1967), The Discovery of Grounded Theory: Strategies of Qualitative Research, Aldine de Gruyter, New York.

Granot E., Brasher M., Motta P. (2012), A structural guide to in-depth interviewing in business and industrial marketing research, "Journal of Business and Industrial Marketing”, Vol. 27 (7), pp. 547-553

Guba E. (1987) What have we learned about naturalistic evaluation? "Evaluation Practice", Vol. 8, pp. 23-43.

Hair J.F., Black W.C., Babin B.J., Anderson R.E. (2014), Multivariate Data Analysis, Pearson Education Limited, Essex, England.

Henry J. (1990), Practical Sampling, Sage, London.

Jennings G. (2011), Tourism Research, ( $2^{\text {nd }}$ ed.), John Wiley \& Sons, Brisbane. Jordan F., Gibson H. (2004), Let your data do the talking: researching the solo travel experiences of British and American women. [in:] Phillimore J., Goodson L., eds., Qualitative Research in Tourism: Epistemologies, Ontologies and Methodologies, Routledge, London, pp. 215-235.

Judd C.M., Smith E.R., Kidder L.H. (1991), Research Methods in Social Relations, ( $6^{\text {th }}$ ed.), Holt, Rinehart, and Winston, New York.

Khoo-Lattimore K., Mura P., Yung R. (2019), The time has come: a systematic literature review of mixed methods research in tourism, "Current Issues in Tourism", Vol. 22, pp. 1531-1550.

Krueger R.A. (1994), Focus Groups: A Practical Guide for Applied Research, $\left(2^{\text {nd }}\right.$ ed.), Sage, London.

Lincoln N., Guba, E. (1985), Naturalistic Enquiry, Sage, Newbury Park.

Marshall C., Rossman, G.B. (1995), Designing Qualitative Research, (2 ${ }^{\text {nd }}$ ed.), Sage, London.

Mason P. (2014), Researching Tourism, Leisure and Hospitality for your Dissertation, Goodfellow, Oxford.

Mason P. (2017), Geography of Tourism: Image, Impacts and Issues, Goodfellow, Oxford.

Mason P., Augustyn M.M., Seakhoa-King A. (2010), Exploratory study in tourism: Developing an initial qualitative phase of sequenced mixed methods research, "International Journal of Tourism Research", Vol. 12 , pp. $432-448$.

Maykut P., Morehouse R. (1994), Beginning Qualitative Research: A Philosophic and Practical Guide, The Falmer Press, London. 
Maykut P., Morehouse R. (2002), Beginning Qualitative Research, Routledge, London.

Miller D.C. (1991), Handbook of Research Design and Social Measurement, Sage, London.

Miller J.A. (1977), Exploring satisfaction, modifying models, eliciting expectations, posing problems, and making meaningful measurements. [in:] Hunt H.K., ed., Conceptualisation and Measurement of Customer Satisfaction and Dissatisfaction Marketing Science Institute, Cambridge, MA, pp. 72-91.

Minjoon J., Peterson R.T., Zsidisin G.A. (1998), The identification and measurement of quality dimensions in health care: focus group interview results. "Health Care Management Review", Vol. 23, pp. 81-97.

Morgan D.L. (1988), Focus Groups as Qualitative Research. Sage, Newbury Park.

Moser C.A., Kalton G. (1975), Survey Methods in Social Investigations, (2 ${ }^{\text {nd }}$ ed.), Heinemann Educational Books, London.

Nunnally J.C. (1967), Psychometric Theory, McGraw Hill, New York.

Oppenheim A.N. (1992), Questionnaire Design, Interviewing and Attitude Measurement, Printer Publishers, London.

Pallant J. (2013), SPSS Survival Manual, McGraw-Hill Education, UK.

Patton M.Q. (1990), Qualitative Evaluation Methods, (2 ${ }^{\text {nd }}$ ed.), Sage, Newbury Park.

Perreault W.D. Jr., Leigh L.E. (1989), Reliability of nominal data based on qualitative judgments. "Journal of Marketing Research", Vol. 26, pp. 135-48.

Phillimore J., Goodson L. (2004), Progress in qualitative research in tourism: epistemology, ontology and methodology. [in:] Phillimore J., Goodson, L., eds., Qualitative Research in Tourism: Epistemology, Ontology, and Methodologies, Routledge, London, pp. 4-29.

Riley R.W., Love L.L. (2000), The state of qualitative tourism research. "Annals of Tourism Research", Vol. 27, pp. 164-187.

Ryan C. (1995), Researching Tourist Satisfaction: Issues, Concepts, Problems, Routledge, London.

Ryan C. (2000), Tourist experiences, phenomenographic analysis, post-positivism and neural network software. "International Journal of Tourism Research", Vol. 2, pp.119-131.

Saunders M., Lewis P., Thornhill A. (2009), Research Methods for Business Students, Pitman, London.

Seakhoa-King A., Augustyn M.M., Mason P. (2021), Tourism Destination Quality: Attributes and Dimensions, Emerald, Bingley, UK.

Sekaran U., Bougie R. (2016), Research Methods for Business: A Skill Building Approach, John Wiley \& Sons, London. 
Smith J., Heshusius L. (1987), Closing down the conversation, The end of the quantitative-qualitative debate among educational researchers, "Educational Researcher", Vol. 15, pp. 4-12.

Sinkovics R.R., Penz E., Ghauri P.N. (2005), Analysing textual data in international marketing research, "Qualitative Market Research: An International Journal”, Vol. 8, pp. 9-38.

Stebbins R.A. (2001), Exploratory Research in the Social Sciences, London, Sage.

Sudman S., Bradburn N.M. (1982), Asking Questions: A Practical Guide to Questionnaire Design. Jossey-Bass, San Francisco, CA.

Tabachnick B.G., Fidell L.S. (1996), Using Multivariate Statistics, (3 ${ }^{\text {rd }}$ ed), Collins, New York.

Tabachnick B.G., Fidell L.S. (2007), Using Multivariate Statistics, (5 ${ }^{\text {th }}$ ed), Allyn and Bacon, New York.

Tashakkori A., Cresswell J. (2007), Exploring the nature of research questions in mixed methods research, "Journal of Mixed Methods Research", Vol. 1, pp. 3-7.

Tashakkori A., Teddlie A. (2003) Handbook of mixed methods in social and behavioural research, SAGE, Thousnsand Oaks, CA

Teddlie A., Tashakorri A. (2009), Foundations of Mixed Methods Research, Sage, London.

Timans R., Wouters P., Heilbron J. (2019), Mixed Methods Research: What is it and What could it be?, "Theory and Society", Vol. 48, pp. 193-126.

Tinsley H.O., Tinsley D. (1987), Uses of factor analysis in counselling psychology research, "Journal of Counselling Psychology", Vol. 34, pp. 414424.

Veal A.J. (2011), Research Methods for Leisure and Tourism: A Practical Guide, ( $3^{\text {rd }}$ ed.), Financial Times Management, London.

Walle A.H. (1997), Quantitative versus qualitative tourism research, "Annals of Tourism Research", Vol. 24, pp. 524-536.

Wengraf T. (2001), Qualitative Research Interviewing: Biographic Narrative and Semi-Structured Methods, Sage, Thousand Oaks, CA.

Zikmund W.G., Carr J.C., Griffin M. (2013), Business Research Methods, Cengage Learning, Mason, $\mathrm{OH}$. 